\title{
Mechanical Behavior of the Weld Joints of Thick Steel Plates Produced by Various Welding Processes
}

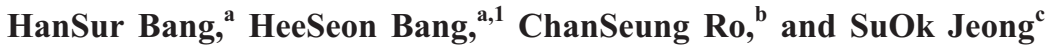 \\ ${ }^{a}$ Department of Welding and Joining Science Engineering, Chosun University, Gwangju, Republic of \\ Korea \\ ${ }^{\mathrm{b}}$ Department of Naval Architecture \& Mechanics, Chosun College of Science \& Technology, \\ Gwangju, Republic of Korea \\ ${ }^{c}$ Department of Welding and Joining Science Engineering, Graduate School, Chosun University, \\ Gwangju, Republic of Korea \\ ${ }^{1}$ banghs@chosun.ac.kr
}

The effect of a welding process (electrogas welding (EGW) and flux cored arc welding (FCAW)) on the fracture toughness, CTOD (crack tip opening displacement), and mechanical properties (tensile, bending, impact strengths and hardness) of thick weld joints is examined. The CTOD value of the $F C A W$ weld joints was higher than that of the EGW ones. The fractured welded specimen after the CTOD test reveals ductile and cleavage fractures of the weld joint faces after flux cored arc and electrogas weldings, respectively. The mechanical properties of the EGW welded specimens satisfied relevant classification rules. These results suggest that the EGW process is an effective substitute for the current welding process (FCAW) used for high-strength thick steel plates.

Keywords: heavy thick steel, electro gas welding, flux cored arc welding, fracture toughness, mechanical properties.

Introduction. The enlargement of container ships offers many economic benefits, such as a reduction in investment costs and shipping expenses [1-4]. In the case of container ships, which possess several holds specifically for loading containers, heavy thick steel plate is generally used for the upper deck and hatch coating because they withstand stress concentrations to achieve stability in their structures [5-8]. In manufacturing the heavy thick steel member, the highly efficient manufacturing technique of the electro gas welding (EGW) process, which involves a large heat input process, is practically unavoidable due to the limitations of the current flux cored arc welding (FCAW) process of the conventional multilayer welding process in terms of productivity [9-14]. On the other hand, EGW is expected to have weaker fatigue strength and undergo brittle fracture due to its large heat input. Some classification societies are considering the relevant requirements to estimate and improve the fracture toughness of large-sized welding constructions using high strength heavy thick steel plates. Therefore, for the application of EGW to a heavy thick hull, the fracture behavior and mechanical characteristics of its welded joints should be clarified in advance. In this study, the fracture toughness (CTOD) was measured and mechanical tests (tensile, impact, bending strength and hardness) were performed to evaluate the strength of the welded joints with high strength $(355 \mathrm{MPa})$ and thick steel plates EH36-TMCP $(78 \mathrm{~mm})$. The results of EGW are compared with those of the current FCAW process.

1. Experimental. In this study, shipbuilding steel plate EH36-TMCP (Classification Grade) with a $78 \mathrm{~mm}$ thickness, which is used in large container ships, was used to fabricate welded specimens by large heat input welding (EGW), and existing multi-layer welding (FCAW). Tables 1 and 2 provide the chemical composition and mechanical properties of the EH36-TMCP and welding electrodes. The specimen dimensions were

(C) HanSur BANG, HeeSeon BANG, ChanSeung RO, SuOk JEONG, 2015 
$\mathrm{T}$ a b 1 e 1

Chemical Composition of EH36-TMCP and Wire (wt.\%)

\begin{tabular}{|c|c|c|c|c|c|c|c|c||}
\hline Material & $\mathrm{C}$ & $\mathrm{Si}$ & $\mathrm{Mn}$ & $\mathrm{P}$ & $\mathrm{S}$ & $\mathrm{Ni}$ & $\mathrm{Cu}$ & $\mathrm{Ti}$ \\
\hline EH36-TMCP & 0.18 & $0.1-0.5$ & $0.9-1.6$ & 0.035 & 0.035 & 0.40 & 0.35 & 0.02 \\
\hline Wire for EGW & 0.05 & 0.25 & 1.6 & 0.009 & 0.007 & 1.40 & - & 0.05 \\
\hline Wire for FCAW & 0.04 & 0.38 & 1.1 & 0.012 & 0.010 & 1.55 & - & - \\
\hline
\end{tabular}

$\mathrm{T}$ a b 1 e 2

Mechanical Properties of EH36-TMCP and Wire

\begin{tabular}{|c|c|c|c||}
\hline Material & Yield strength (MPa) & Tensile strength (MPa) & Elongation (\%) \\
\hline EH36-TMCP & 355 & $490-620$ & 21 \\
\hline Wire for EGW & 500 & 615 & 25 \\
\hline Wire for FCAW & 560 & 620 & 29 \\
\hline
\end{tabular}

$\mathrm{T}$ a b 1 e 3

Welding Condition for the EGW Specimens

\begin{tabular}{|c|c|c|c|c|c|c|}
\hline $\begin{array}{c}\text { Number } \\
\text { of pass }\end{array}$ & $\begin{array}{c}\text { Current } \\
(\mathrm{A})\end{array}$ & $\begin{array}{c}\text { Voltage } \\
(\mathrm{V})\end{array}$ & $\begin{array}{c}\text { Arc time } \\
(\mathrm{s})\end{array}$ & $\begin{array}{c}\text { Speed } \\
(\mathrm{cm} / \mathrm{min})\end{array}$ & $\begin{array}{c}\text { Interpass } \\
\text { temperature } \\
\left({ }^{\circ} \mathrm{C}\right)\end{array}$ & $\begin{array}{c}\text { Heat input } \\
(\mathrm{kJ} / \mathrm{cm})\end{array}$ \\
\hline Top (1 pass) & 400 & 42 & 1589 & 4.5 & 116 & 235.2 \\
\hline Bottom (1 pass) & 430 & 44 & 1310 & 5.5 & 162 & 206.4 \\
\hline
\end{tabular}
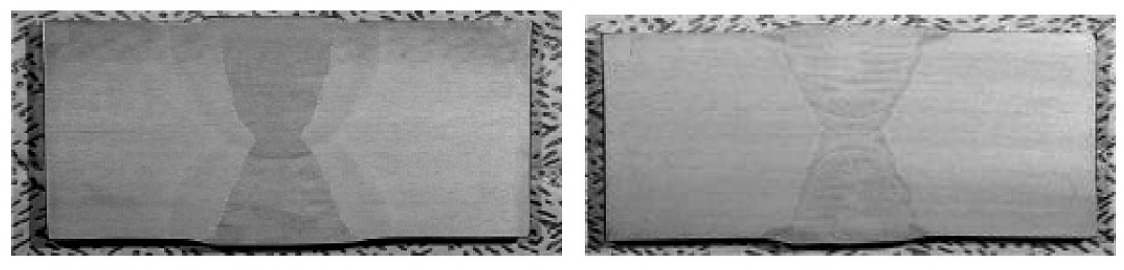

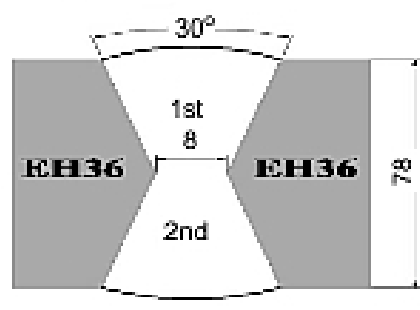

a

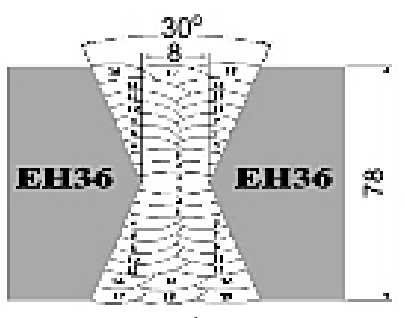

$\mathrm{b}$

Fig. 1. Welding joint shape and number of layers for the EGW (a) and FCAW (b) process.

$1200 \mathrm{~mm}$ in length, $400 \mathrm{~mm}$ in breadth and complied with the requirements of the WPQT (welding procedure qualification test) of the classification societies. The shape and angle of the welding groove were chosen to have an $\mathrm{X}$ shape in both sides, $30^{\circ}$ in the bevel angle and an $8 \mathrm{~mm}$ gap, considering the field conditions of welding. Figure 1, as well as Tables 3 and 4 provide the details of the welding joint shape and the number of layers for the EGW and FCAW welded joints, respectively. 
HanSur Bang, HeeSeon Bang, ChanSeung Ro, and SuOk Jeong

$\mathrm{T}$ a b 1 e 4

Welding Conditions for the FCAW Specimens

\begin{tabular}{|c|c|c|c|c|c|c|c|c|c|}
\hline \multicolumn{2}{|c|}{ Number of pass } & \multirow{2}{*}{\multicolumn{2}{|c|}{$\begin{array}{l}\text { Current } \\
\text { (A) }\end{array}$}} & \multirow{2}{*}{\multicolumn{2}{|c|}{$\begin{array}{l}\text { Voltage } \\
\text { (V) }\end{array}$}} & \multirow{2}{*}{\multicolumn{2}{|c|}{$\begin{array}{l}\text { Arc time } \\
\text { (s) }\end{array}$}} & \multirow{2}{*}{\multicolumn{2}{|c|}{$\begin{array}{c}\text { Interpass } \\
\text { temperature }\left({ }^{\circ} \mathrm{C}\right)\end{array}$}} \\
\hline Top & Bottom & & & & & & & & \\
\hline 1 & 1 & 240 & 300 & 30 & 31 & 405 & 373 & 119 & 119 \\
\hline 2 & 2 & 280 & 300 & 31 & 31 & 352 & 361 & 123 & 135 \\
\hline 3 & 3 & 300 & 300 & 31 & 31 & 365 & 359 & 114 & 157 \\
\hline 4 & 4 & 300 & 280 & 31 & 32 & 143 & 223 & 123 & 128 \\
\hline 5 & 5 & 300 & 280 & 31 & 32 & 182 & 209 & 141 & 147 \\
\hline 6 & 6 & 300 & 280 & 31 & 32 & 193 & 262 & 137 & 130 \\
\hline 7 & 7 & 300 & 280 & 31 & 32 & 172 & 191 & 131 & 112 \\
\hline 8 & 8 & 300 & 310 & 31 & 31 & 151 & 265 & 115 & 129 \\
\hline 9 & 9 & 300 & 310 & 31 & 31 & 174 & 262 & 119 & 145 \\
\hline 10 & 10 & 300 & 320 & 31 & 31 & 147 & 244 & 131 & 125 \\
\hline 11 & 11 & 300 & 320 & 31 & 31 & 199 & 226 & 149 & 136 \\
\hline 12 & 12 & 300 & 320 & 31 & 31 & 151 & 237 & 127 & 115 \\
\hline 13 & 13 & 300 & 320 & 31 & 31 & 201 & 246 & 139 & 118 \\
\hline 14 & 14 & 260 & 320 & 29 & 31 & 131 & 212 & 152 & 124 \\
\hline 15 & 15 & 260 & 320 & 29 & 31 & 171 & 187 & 121 & 131 \\
\hline 16 & 16 & 260 & 320 & 29 & 31 & 121 & 257 & 147 & 135 \\
\hline 17 & 17 & 260 & 275 & 29 & 31 & 117 & 213 & 114 & 105 \\
\hline 18 & 18 & 260 & 275 & 29 & 31 & 153 & 227 & 127 & 111 \\
\hline- & 19 & - & 275 & - & 31 & - & 176 & - & 125 \\
\hline
\end{tabular}

The CTOD test of the $B \times B$ type using a 3-point bending test was carried out in accordance with the BS7448 Standard to examine the fracture toughness in the fusion line where lowest fracture toughness might be encountered [11-14]. The CTOD test was performed for two types of surface notch and through thickness notch, which are located on CGHAZ, as shown in Fig. 2. Furthermore, tests for the mechanical properties, i.e., tensile, bending, impact strength, and hardness were performed and evaluated according to the class rules. The tensile strength tests were conducted on the half-thickness specimens with a size of $25 \mathrm{~mm}(W) \times 39 \mathrm{~mm}(t)$. Side bending tests were carried out with an angle of $180^{\circ}$. A Charpy impact test was performed at each notch location of the face and middle part, such as the weld metal, fusion line, fusion line $+1,+2,+3$, and $+5 \mathrm{~mm}$ at $-20^{\circ} \mathrm{C}$.

Figures 3 and 4 show the procedure for the CTOD test by the 3-point bending specimen and a schematic diagram of the CTOD values calculation, respectively. The test procedure requires that the radius of the milled notch and band swan notch shall not exceed $0.1 \mathrm{~mm}$ in radius and $0.15 \mathrm{~mm}$ in breadth. This means that if the dimensions of the specimen failed to satisfy the dimension requirements, no further test is performed, and the test will be invalidated if the fatigue crack size including the notch length exceeds $60 \%$ of the breadth $(W)$, which was fixed by the specimen thickness $(B)$, in the base metal and $70 \%$ in the weld metal. During the test, a fatigue crack induced by a 500 ton class universal fatigue test machine was initiated with a stress ratio $R=0.1$. 


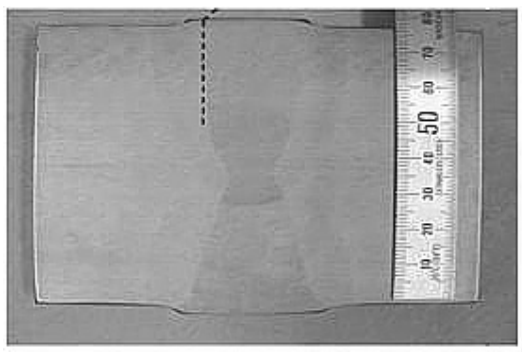

a

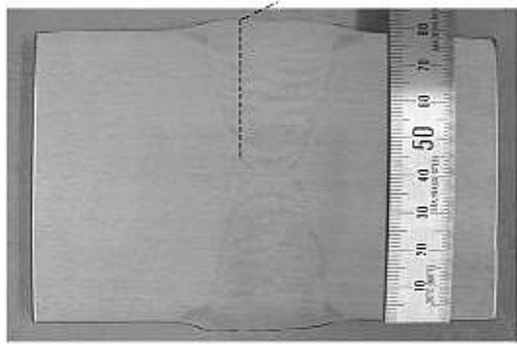

c

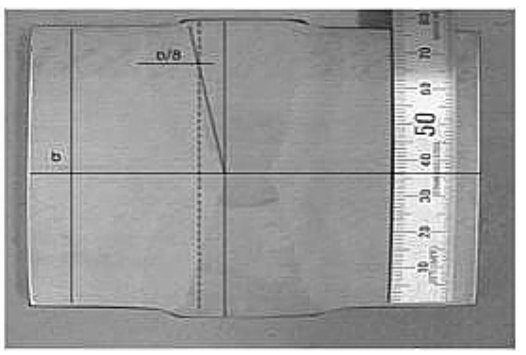

b

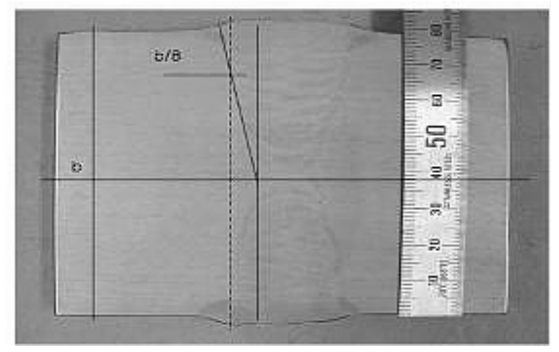

d

Fig. 2. Notch locations of the EGW (a, b) and FCAW (c, d) welded specimens: (a, c) through-thickness notch; (b, d) surface notch.

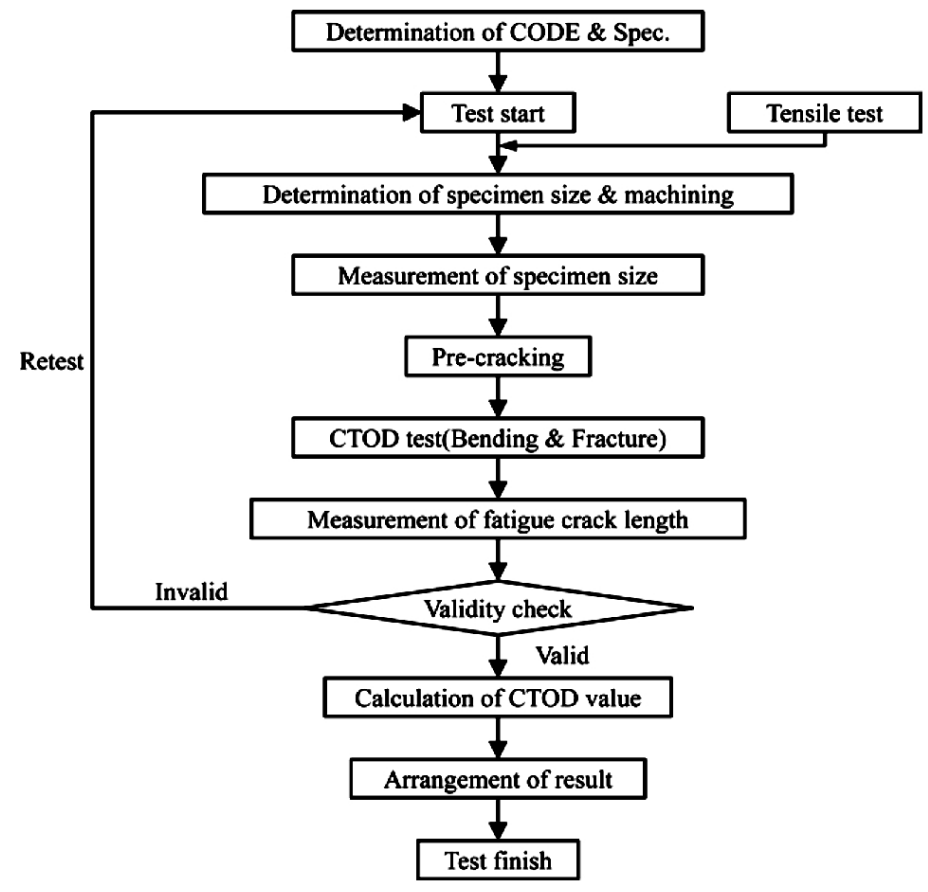

Fig. 3. CTOD test procedure.

After the fatigue crack formation, the 3-point bending test was carried out after maintaining the specimen in the refrigerant chamber at a test temperature $-20^{\circ} \mathrm{C}$ of $\mathrm{E}$ grade steel. In order to create test temperature $-20^{\circ} \mathrm{C}$, refrigerant liquid nitrogen in chamber was maintained in the temperature range $-20 \pm 2^{\circ} \mathrm{C}$ and specimen was dipped into refrigerant 


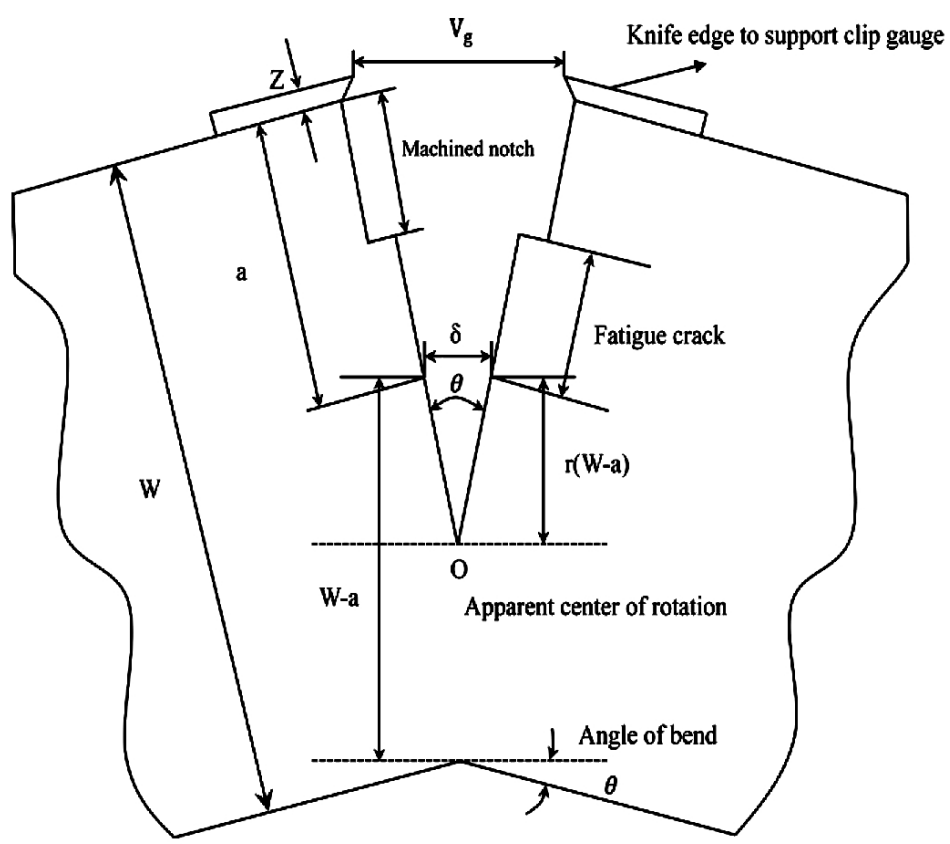

Fig. 4. Schematic diagram of the CTOD values calculation.

liquid nitrogen for $30 \mathrm{~s}$ per thickness of specimen. During and after the test, a measurement of the crack opening displacement (COD) with plastic component of the clip gauge displacement $V_{p}, P_{m}$ value and evaluation of the fractured surface and crack length $a_{0}$ were conducted. Figure 3 schematically depicts the test procedure. In addition, the fatigue crack length should comply with the following criteria: (i) crack length to specimen breadth ratio $a_{0} / W$ should be within the range from 0.45 to 0.55 ; (ii) the crack length increment (difference between any two sets of values) should not exceed $10 \%$ of $a_{0}$; and (iii) crack propagated angle from the notch direction should not exceed $10^{\circ}$.

From the available methods for the CTOD test conduction, an estimation method by the displacement of a clip gauge was selected, which is based on a rotating center. In this method, the specimen is treated as a rotating rigid body on $r(W-a)$ as the central axis from the crack tip when a bending load is applied, and using relationships between the resulting $\delta$ and $V_{g}$, the CTOD can be estimated as follows:

$$
\Phi=\frac{r(W-a) V_{p}}{a+z+r(W-a)} V_{g},
$$

where $r$ is the rotation factor. In accordance with the BS 5762 for the 3-point bending test, the $\operatorname{CTOD}(\Phi)$ for $r=0$ can be described as follows:

$$
\delta=\frac{K^{2}\left(1-v^{2}\right)}{2 \sigma_{Y} E}+\frac{0.4(W-a) V_{p}}{0.4 W+0.6 a+z},
$$

where $K$ is stress intensity factor, $v$ is Poisson's ratio, $\sigma_{Y}$ is the yield strength, $E$ is the Young modulus, $a$ is the effective crack length, $V_{p}$ is the plastic component of the clip gauge displacement, and $z$ is the distance between the clip gauge location from the test piece surface. 


\section{Results and Discussion.}

2.1. Fracture Toughness. Table 5 presents the results of the CTOD test of the EGW and FCAW welded specimens with a surface notch and through thickness notch, whose locations in the welded specimens are shown in Fig. 2. Figures 5 and 6 show the fractured welded specimens after the CTOD test. The CTOD values of the EGW for the surface notch and through thickness notch, which are located on CGHAZ, were 0.212 and $0.687 \mathrm{~mm}$, respectively, whereas the values of the FCAW were 0.403 and $0.939 \mathrm{~mm}$. The CTOD value in FCAW was higher than that of EGW and the values on the surface notch, where the microstructure is weak at the crack tip, was less than those of the through thickness notch. The fractured surface after the CTOD test for the EGW and FCAW welded specimens were observed by SEM (scanning electron microscopy), as shown in Figs. 7 and 8. The shape of the fracture face in EGW shows that facet fracture occurs, as observed from the plain surface on the fractured face, whereas the FCAW shows the facet fracture together with the partial dimple fracture. This means that the FCAW shows ductile fracture due to the low heat input and small grain boundary but EGW shows cleavage fracture due to the high heat input, large granule sand brittleness. In the case of EGW, there was no difference in the fractured faces between the surface and through thickness notch.

$\mathrm{T}$ a b 1 e 5

Results of the CTOD Test

\begin{tabular}{|c|c|c||}
\hline Welding process & Location of crack & CTOD value $(\mathrm{mm})$ \\
\hline \multirow{2}{*}{ EGW } & Surface notch & 0.212 \\
\cline { 2 - 3 } & Through-thickness notch & 0.687 \\
\hline \multirow{2}{*}{ FCAW } & Surface notch & 0.403 \\
\cline { 2 - 3 } & Through-thickness notch & 0.939 \\
\hline
\end{tabular}

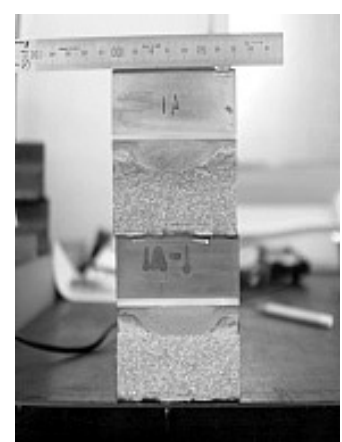

a

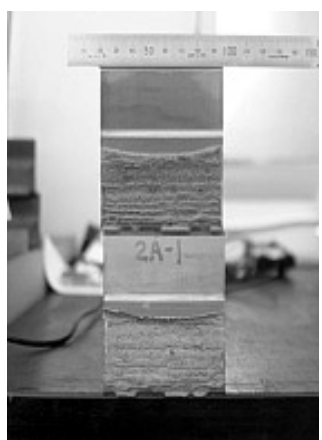

$\mathrm{b}$

Fig. 5. Fractured EGW welded specimen after the CTOD test: surface notch (a) and through-thickness notch (b).

2.2. Mechanical Properties. Table 6 lists the results of the tensile tests for the EGW and FCAW welded specimens. All specimens were fractured by the base metal and the mean tensile strengths were measured to be approximately $540 \mathrm{MPa}$ for the EGW and FCAW specimens, which satisfied the classification requirements (min. $470 \mathrm{MPa}$ ) for EH36-TMCP. The hardness test for each welding process was carried out using a Vickers hardness tester throughout 22 points for the weld metal (WM), heat affected zone (HAZ), and base metal (BM), as shown in the photos embedded into Table 7. A comparison of the hardness between the front and the backward welding regions revealed the value of the 
HanSur Bang, HeeSeon Bang, ChanSeung Ro, and SuOk Jeong

$\mathrm{T}$ a $\mathrm{b} 1 \mathrm{e} 6$

Tensile Test Results for the EGW and FCAW Welded Specimens

\begin{tabular}{|c|c|c|c|c|c|}
\hline Item & $\begin{array}{c}\text { Size } \\
(W \times t, \mathrm{~mm})\end{array}$ & $\begin{array}{l}\text { Area } \\
\left(\mathrm{mm}^{2}\right)\end{array}$ & $\begin{array}{l}\text { Total load } \\
\text { (ton) }\end{array}$ & $\begin{array}{c}\text { Tensile strength } \\
(\mathrm{MPa})\end{array}$ & Note \\
\hline EGW 1 & $25.0 \times 40.2$ & 1005.00 & 55.60 & 542.16 & \multirow{4}{*}{$\begin{array}{c}\text { Mean } \\
\text { tensile } \\
\text { strength } \\
539.66 \mathrm{MPa}\end{array}$} \\
\hline EGW 2 & $25.6 \times 35.3$ & 903.68 & 49.80 & 540.05 & \\
\hline EGW 3 & $25.4 \times 38.5$ & 977.90 & 53.30 & 540.25 & \\
\hline EGW 4 & $24.9 \times 37.8$ & 941.22 & 50.85 & 536.17 & \\
\hline FCAW 1 & $25.3 \times 38.0$ & 961.40 & 52.60 & 536.17 & \multirow{4}{*}{$\begin{array}{c}\text { Mean } \\
\text { tensile } \\
\text { strength } \\
540.17 \mathrm{MPa}\end{array}$} \\
\hline FCAW 2 & $35.3 \times 37.5$ & 948.75 & 51.30 & 529.89 & \\
\hline FCAW 3 & $25.3 \times 37.3$ & 943.69 & 51.95 & 539.48 & \\
\hline FCAW 4 & $24.9 \times 37.8$ & 941.22 & 52.25 & 555.13 & \\
\hline
\end{tabular}

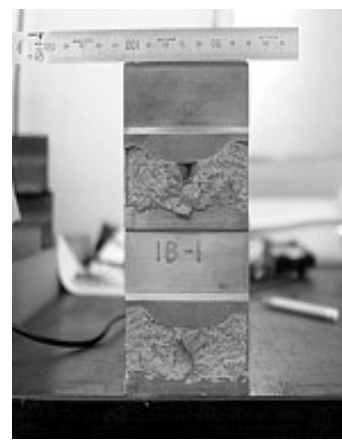

a

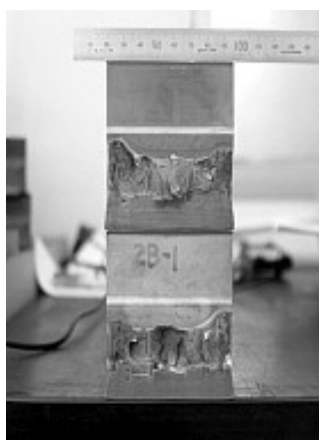

b

Fig. 6. Fractured FCAW welded specimen after the CTOD test: surface notch (a) and through-thickness notch (b).
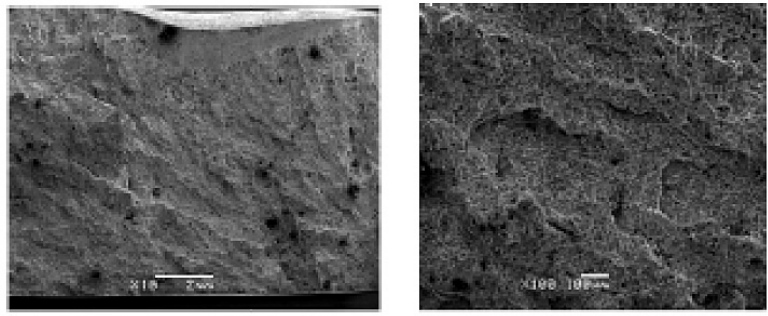

Fig. 7. SEM images of the fractured surfaces after the CTOD test of the EGW welded specimen.
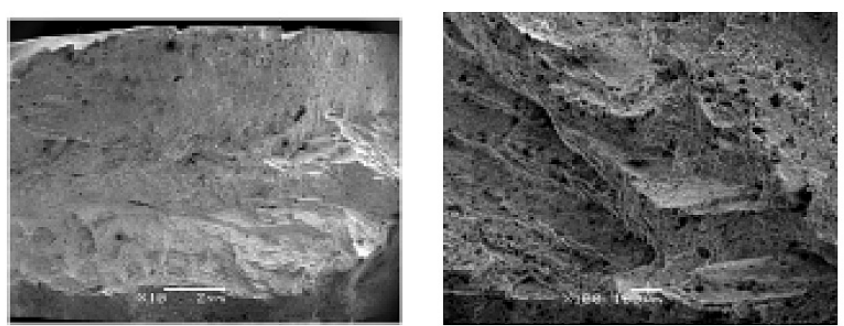

Fig. 8. SEM images of the fractured surfaces after the CTOD test of the FCAW welded specimen. 
T a b 1 e 7

\section{Hardness Test Results for the EGW and FCAW Welded Specimens}

\begin{tabular}{|c|c|c|c|c|c|c|c|c|c|c|c|}
\hline \multicolumn{11}{|c|}{ EGW welded specimens } & Measurement points/EGW \\
\hline $\mathrm{BM}$ & \multicolumn{3}{|c|}{ HAZ (left) } & \multicolumn{3}{|c|}{ WM } & \multicolumn{3}{|c|}{ HAZ (right) } & $\mathrm{BM}$ & \multirow{6}{*}{ 要 } \\
\hline 1 & 2 & 3 & 4 & 5 & 6 & 7 & 8 & 9 & 10 & 11 & \\
\hline 206 & 174 & 185 & 175 & 215 & 215 & 209 & 191 & 187 & 190 & 214 & \\
\hline BM & \multicolumn{3}{|c|}{ HAZ (left) } & \multicolumn{3}{|c|}{ WM } & \multicolumn{3}{|c|}{ HAZ (right) } & $\mathrm{BM}$ & \\
\hline 12 & 13 & 14 & 15 & 16 & 17 & 18 & 19 & 20 & 21 & 22 & \\
\hline 210 & 199 & 204 & 218 & 232 & 235 & 236 & 207 & 216 & 212 & 211 & \\
\hline \multicolumn{11}{|c|}{ FCAW welded specimens } & Measurement points/FCAW \\
\hline BM & \multicolumn{3}{|c|}{ HAZ (left) } & \multicolumn{3}{|c|}{ WM } & \multicolumn{3}{|c|}{ HAZ (right) } & $\mathrm{BM}$ & \multirow{6}{*}{ 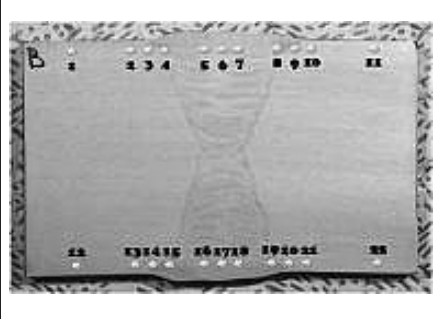 } \\
\hline 1 & 2 & 3 & 4 & 5 & 6 & 7 & 8 & 9 & 10 & 11 & \\
\hline 194 & 217 & 212 & 207 & 212 & 218 & 218 & 231 & 223 & 210 & 190 & \\
\hline $\mathrm{BM}$ & \multicolumn{3}{|c|}{ HAZ (left) } & \multicolumn{3}{|c|}{ WM } & \multicolumn{3}{|c|}{ HAZ (right) } & $\mathrm{BM}$ & \\
\hline 12 & 13 & 14 & 15 & 16 & 17 & 18 & 19 & 20 & 21 & 22 & \\
\hline 186 & 229 & 246 & 241 & 204 & 225 & 220 & 232 & 225 & 222 & 198 & \\
\hline
\end{tabular}

T a b 1 e 8

Results of the Bending Test for the EGW and FCAW Welded Specimens

\begin{tabular}{|c|c|c|c|c|c||}
\hline Item & Type & $\begin{array}{c}\text { Angle } \\
(\mathrm{deg})\end{array}$ & Requirement & Result & $\begin{array}{c}\text { Welded specimen } \\
\text { after bending test }\end{array}$ \\
\hline $\begin{array}{c}\text { EGW } \\
1-4\end{array}$ & $\begin{array}{c}\text { Side } \\
\text { bend }\end{array}$ & 180 & $\begin{array}{c}\text { Open defect } \\
\text { length } \leq 3 \mathrm{~mm}\end{array}$ & Accepted & Accepted \\
\hline $\begin{array}{c}\text { FCAW } \\
1-4\end{array}$ & $\begin{array}{c}\text { Side } \\
\text { bend }\end{array}$ & 180 & $\begin{array}{c}\text { Open defect } \\
\text { length } \leq 3 \mathrm{~mm}\end{array}$ & & \\
\hline
\end{tabular}

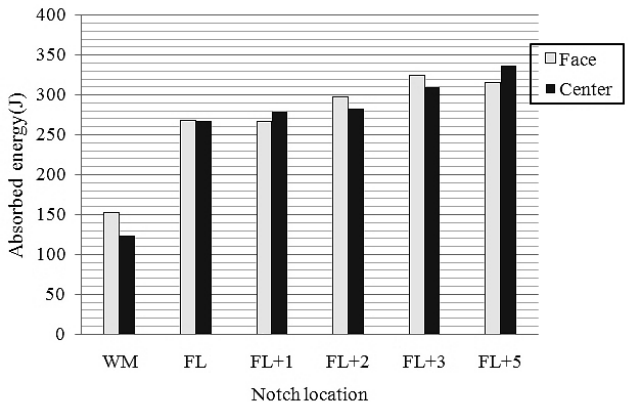

a

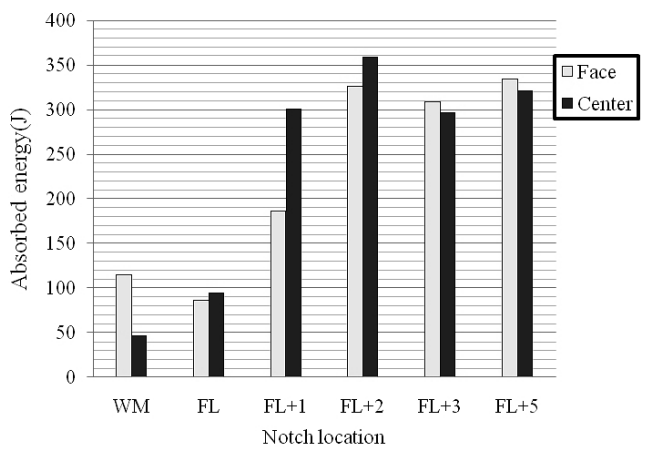

b

Fig. 9. Results of the impact test for the EGW (a) and FCAW (b) welded specimens. 
backward side to be higher than the front side. This confirmed that the test results satisfied the relevant standards, such as HV for the weld and $350 \mathrm{HV}$ for the HAZ, as shown in Table 7. In addition, this result also complied with the mechanical properties of an EH36-TMCP steel plate.

Figure 9 shows the absorbed energy, which was tested using the Charpy impact test at a test temperature of $-20^{\circ} \mathrm{C}$. The test results show that the energy absorbed at each notch location of the face and middle parts, such as the weld metal, fusion line, fusion line +1 , $+2,+3$, and $+5 \mathrm{~mm}$, was sufficient $(>150 \mathrm{~J})$. In addition, these results satisfied the relevant standard, i.e., min. $34 \mathrm{~J}$ in the EGW specimens and $47 \mathrm{~J}$ in the FCAW specimens. The bending strength of the EGW and the FCAW welded specimens was estimated. As shown in Table 8, no open defect occurred, which satisfies the relevant requirements of an open defect length $\leq 3 \mathrm{~mm}$.

Conclusions. In view of the structural integrity and stability for a welding construction that uses heavy thick plate, these results show that large heat input welding, such as EGW, complies with the relevant requirements. The comparison with the traditional welding process, FCAW, shows that the EGW welded joints are compatible with large welding constructions.

Acknowledgments. This research was financally supported by the Ministry of Education, Science Technology (MEST) and National Research Foundation of Korea (NRF) through the human resource training project for regional innovation (2012H1B8A2026193).

1. D. J. Park, H. Kim, and K. C. Nam, "An empirical study on the economical benefit of space chartering," J. Kor. Nav. Port Res., 30, No. 8, 663-668 (2006).

2. C. G. Kim, "A study on the trend and its limitation of building large container ship to reduce the logistics cost," in: The Korean Association of Shipping and Logistics (2002).

3. http://www.intport.org/html/sub2_2.html

4. C. I. Hsu and Y. P. Hsieh, "Shipping economic analysis for ultra large container ship," J. East. Asia Soc. Transport. Stud., 6, 936-951 (2005).

5. K. K. Um, S. H. Kim, et al., "High performance steel plates for shipbuilding applications," in: Proc. of 18th International Offshore and Polar Engineering Conference (July 6-11, 2008, Vancouver, Canada), International Society of Offshore and Polar Engineers (2008), ISOPE-I-08-317.

6. S. H. Kim, I. S. Suh, and K. B. Kan, Development of TMCP Steel Plate for Shipbuilding Application, Posco Technical Report, No. 10 (2006).

7. S. Suzuki, R. Muraoka, T. Obinata, et al., Steel Products for Shipbuilding, JFE Technical Report, No. 2 (2004).

8. M. Minagawa, K. Ishida, Y. Funatsu, et al., 390 MPa Yield Strength Steel Plate for Large Heat-Input Welding for Large Container Ships, Nippon Steel Technical Report, No. 90 (2004), pp. 7-10.

9. K. Sasaki, K. Suda, R. Motomatsu, et al., Development of Two-Electrode Electrogas Arc Welding Process, Nippon Steel Technical Report, No. 90 (2004), pp. 67-74.

10. S. Suzuki, K. Ichimiya, and T. Akita, High Tensile Strength Steel Plates with Excellent HAZ Toughness for Shipbuilding, JFE Technical Report, No. 5 (2005).

11. C. M. Kim, J. B. Lee, and W. Y. Choo, "Characteristics of single pass welds in 50 $\mathrm{kJ} / \mathrm{mm}$ of heavy thickness shipbuilding steel," in: Proc. of 13rd Int. Offshore and Polar Engineering Conference (May 25-30, 2003, Honolulu, Hawaii, USA) (2003). 
12. H. C. Jeong, Y. H. Park, Y. H. An, and J. B. Lee, "Mechanical properties and micro structures of high heat input welded tandem EGW joint in EH36-TM steel," J. Korean Weld. Join. Soc., 25, No. 1, 57-62 (2007).

13. J. S. Park, G. B. An, B. Y. Jung, and J. B. Lee, "Effect of welding heat input on the crack arrestability of thick steel plate welds," in: Proc. of 18th Int. Offshore and Polar Engineering Conference (July 6-11, 2008, Vancouver, Canada) (2008).

14. T. Inoue, T. Ishikawa, S Imai, et al., "Long crack arrestability of heavy-thick shipbuilding steels," in: Proc. of 18th Int. Offshore and Polar Engineering Conference (July 6-11, 2008, Vancouver, Canada) (2008).

Received 20. 10. 2014 